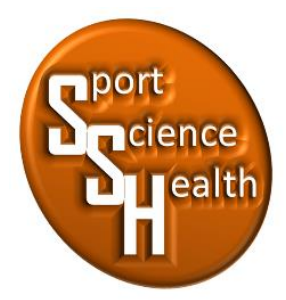

ISSN 2715-3886

\title{
Pengembangan Pembelajaran Kebugaran Jasmani Unsur Kelincahan Berbasis Multimedia Interaktif
}

\author{
Muhammad Ghazali Arief ${ }^{1 \star}$, Ari Wibowo Kurniawan ${ }^{2}$, Rama Kurniawan ${ }^{3}$ \\ 1,2,3 Jurusan Pendidikan Jasmani, Kesehatan dan Rekreasi, Fakultas IImu Keolahragaan, \\ Universitas Negeri Malang, Jalan Semarang No 5, Malang, Jawa Timur, 65145, Indonesia \\ *Penulis koresponden: muhammadghazali08@gmail.com, 081331440169
}

Artikel diterima: 2 Januari 2020; direvisi: 18 Februari 2021; disetujui: 22 Februari 2021

\begin{abstract}
This development research aims to develop learning of physical fitness agility elements based on interactive multimedia in SMP Negeri 4 Malang. Using the Research and Development (R\&D) model with Lee \& Owen. Using a small group trial subject of 20 students and a large group trial subject of 60 students consisting of class VII and class VIII. Based on the results of data analysis obtained from learning experts with a percentage of $93 \%$, physical fitness experts with a percentage of $91 \%$, media experts with a percentage of $90 \%$, small group trials $89 \%$, and large group trials $89 \%$. Based on the analysis of the data that has been obtained, it is concluded that the development product is suitable for use in the learning process.
\end{abstract}

Keyword: development, agility, interactive multimedia

\begin{abstract}
Abstrak: Penelitian pengembangan ini bertujuan mengembangkan pembelajaran kebugaran jasmani unsur kelincahan berbasis multimedia interaktif di SMP Negeri 4 Malang. Menggunakan model Reseach and Development (R\&D) dengan Lee \& Owen. Menggunakan subjek uji coba kelompok kecil 20 siswa dan subjek uji coba kelompok besar 60 siswa terdiri dari kelas VII dan kelas VIII. Berdasarkan hasil analisis data yang diperoleh dari ahli pembelajaran dengan persentase $93 \%$, ahli kebugaran jasmani dengan persentase $91 \%$, ahli media dengan persentase $90 \%$, uji coba kelompok kecil $89 \%$, dan uji coba kelompok besar $89 \%$. Berdasarkan analisis data yang telah diperoleh, disimpulkan bahwa produk pengembangan layak digunakan dalam proses pembelajaran.
\end{abstract}

Kata kunci: pengembangan, kelincahan, multimedia interaktif

\section{PENDAHULUAN}

Kegiatan olahraga merupakan suatu bentuk kebudayaan manusia yang paling tua dan sudah dilakukan oleh berbagai jenis suku dan bangsa di dunia ini. Karena olahraga pada dasarnya merupakan suatu kegiatan budaya manusia untuk mempertahankan eksistensi dan kehidupannya. Olahraga sendiri merupakan hasil kreasi dari masyarakat dalam bentuk suatu permainan yang memanfaatkan keadaan di lingkungan sekitarnya, sehingga kegiatan tersebut bermakna dan bermanfaat bagi dirinya serta masyarakat di lingkungannya. Dengan terciptanya suatu permainan olahraga oleh masyarakat, banyak yang menjadikan permainan olahraga tersebut sebagai budaya dari lingkungannya atau budaya di daerahnya tersebut. Bahkan ada pula yang memaknai permainan olahraga tersebut menjadi suatu proses beribadah atau kegiatan dari keagamaan atau kepercayaan masyarakat. Seperti contoh lompat batu (Hompo Batu) di Kepulauan Nias yang dijadikan 
sebagai acara penobatan atau pemberian makna bagi anak remaja yang sudah beranjak dewasa. Jika anak tersebut dapat melompati tugu batu, maka akan dianggap sebagai orang dewasa. Dengan adanya pemaknaan olahraga dalam masyarakat, maka olahraga akan sangat berkembang disuatu wilayah atau negara.

Seiring berjalannya jaman dan perkembangan akal pikir manusia, perkembangan olahraga yang awalnya bersifat hanya untuk bermain-main, kini kegiatan olahraga kini dapat dianalisis sehingga memiliki makna yang lebih luas. Serta dilakukan secara terlembaga dan tersistem, sehingga menjadi suatu kegiatan yang dapat dilakukan oleh masyarakat luas dengan tujuan yang beragam. Kini sebagian besar kegiatan olahraga dimaksudkan atau digunakan sebagai cara untuk meningkatkan kualitas fisik serta kebugaran jasmani dari manusia. Karena kualitas fisik serta kebugaran jasmani sangat penting bagi manusia untuk mempertahankan hidupnya. Dengan terlembaganya kegiatan olahraga, maka olahraga kini termasuk dalam pendidikan. Pendidikan olahraga yang dibina oleh pemerintah melalui Departemen Pendidikan Nasional yaitu pada sekolah tingkat Sekolah Dasar (SD), Sekolah Menengah (SMP dan SMA) dan ditingkat pergutuan tinggi. Pendidikan olahraga di lembaga pendidikan biasa disebut dengan pendidikan jasmani.

Pendidikan jasmani adalah proses pendidikan menggunakan aktivitas fisik yang dilakukan secara sistematik dengan tujuan meningkatkan kemampuan ranah afektif, kognitif, dan psikomotor. Pendidikan jasmani merupakan bagian secara keseluruhan dari proses pendidikan dengan menggunakan aktifitas fisik sebagai alat untuk mencapai tujuan (López-Pastor, Kirk, Lorente-Catalán, MacPhail, \& Macdonald, 2013; Rink, 2013). Tujuan tersebut diantaranya mengembangkan individu secara fisik, sosial, intelektual, dan emosional. Pendidikan jasmani adalah proses pendidikan yang memanfaatkan aktivitas fisik untuk menghasilkan perubahan pada diri peserta didik secara mental, fisik, dan emosional (Harris, Cale, \& Musson, 2012; Johnson, 2016). Pendidikan jasmani merupakan proses pendidikan menggunakan pengalaman belajar berupa aktivitas jasmani, olahraga, dan permainan secara sistematik yang bertujuan untuk meningkatkan pertumbuhan fisik, keterampilan motorik, sosial, moral, dan emosional pada siswa (Harvey \& O'Donovan, 2013; Wallhead, Garn, \& Vidoni, 2014). Pendidikan jasmani merupakan bagian dari pendidikan di sekolah yang tidak dapat dipisah, memiliki tujuan yaitu untuk meningkatkan kemampuan sikap, pengetahuan, dan keterampilan pada peserta didik (Kwon \& Block, 2017; Smith, Monnat, \& Lounsbery, 2015). Pendidikan jasmani merupakan suatu proses mendidik melalui aktivitas jasmani dan olahraga untuk mencapai tujuan pendidikan (Harvey, Kirk, \& O'Donovan, 2014; Solmon, 2015). Tujuan olahraga yaitu memberikan kesempatan kepada anak untuk mempelajari berbagai kegiatan yang membina serta mengembangkan potensi anak dalam aspek sosial, mental, emosional, moral, fisik dan kebugaran jasmani. Untuk mencapai tujuan tersebut maka dalam pendidikan jasmani menggunakan aktivitas jasmani berupa permainan atau olahraga. Disini kebugaran jasmani merupakan hal yang utama karena dengan kondisi jasmani yang baik, maka tujuan-tujuan pendidikan jasmani tersebut dapat terlaksana dengan baik.

Oleh karena itu kebugaran jasmani masuk dalam materi pendidikan jasmani di sekolah. Kebugaran jasmani terdapat dalam kompetensi inti dan kompetensi dasar pendidikan jasmani, olahraga dan kesehatan pada tingkat pendidikan sekolah menengah pertama (SMP) kelas VII dan kelas VIII sesuai dalam lampiran Permendikbud (2018). Berikut butir kebugaran jasmani pada KI dan KD pada tingkat pendidikan SMP kelas VII:

Tabel 1. Kompetensi Dasar Mata Pelajaran Pendidikan Jasmani, Olahraga, dan Kesehatan SMP Kelas VII dan VIII (Lampiran Permendikbud KI dan KD PJOK/MTs K-13 Revisi 2017)

\section{Kompetensi Dasar Kelas VII}

3.5 Memahami konsep latihan peningkatan derajat 4.5 Mempraktikkan latihan peningkatan kebugaran jasmani yang terkait dengan kesehatan (daya tahan, kekuatan, komposisi tubuh, dan derajat kebugaran jasmani yang terkait kelenturan) dan pengukuran hasilnya. dengan kesehatan (daya tahan, kekuatan, komposisi tubuh, dan kelenturan) dan pengukuran hasilnya.

\section{Kompetensi Dasar Kelas VIII}

\begin{tabular}{ll}
\hline $\begin{array}{l}\text { 3.5 Memahami konsep latihan peningkatan derajat } \\
\text { kebugaran jasmani yang terkait dengan keterampilan }\end{array}$ & $\begin{array}{l}\text { Mempraktikkan latihan peningkatan } \\
\text { derajat kebugaran jasmani yang terkait }\end{array}$ \\
$\begin{array}{l}\text { (kecepatan, kelincahan, keseimbangan, dan } \\
\text { koordinasi) serta pengukuran hasilnya, }\end{array}$ & $\begin{array}{l}\text { dengan keterampilan (kecepatan, } \\
\text { kelincahan, keseimbangan, dan } \\
\text { koordinasi) serta pengukuran hasilnya. }\end{array}$ \\
\hline
\end{tabular}


Kebugaran jasmani merupakan kemampuan seseorang melakukan aktifitas fisik tanpa merasa kelelahan yang berlebih dan masih memiliki tenaga yang cukup untuk melaksanakan aktivitas lainnya. Kebugaran jasmani merupakan kemampuan tubuh dalam melakukan aktivitas fisik sehari-hari tanpa merasa kelelahan yang berarti dan masih memiliki tenaga untuk melakukan aktivitas lainnya setelah melakukan aktivitas fisik (Darmawan, 2017; Azizil Fikri, 2017; Prakoso \& Setiyo Hartoto, 2015). Kebugaran jasmani adalah tingkatan sehat dinamis seseorang yang menjadi dasar kemampuan jasmaninya untuk dapat melakukan tugas-tugas yang harus dilakukannya (Lloyd \& Oliver, 2012; Mora-Gonzalez et al., 2019). Kebugaran jasmani merupakan kondisi dimana jasmani menggambarkan suatu potensi serta kemampuan untuk melakukan tugas-tugas tertentu dengan hasil yang optimal tanpa menampakkan kelelahan yang berarti dan masih memiliki cukup energi untuk menghadapi suatu hal atau tugas yang bersifat darurat (Huotari, Mikkelsson, Kujala, Laakso, \& Nupponen, 2013; Milanović et al., 2013). Kebugaran jasmani memiliki beberapa unsur, yaitu kekuatan otot (strenght), daya tahan jantung dan paru (endurance), kelentukan (fleksibilitas), kecepatan (speed), daya eksplosif (power), keseimbangan (balance), kelincahan (agility), koordinasi (coordination) dan ketepatan (accuracy). Dengan adanya unsur-unsur tersebut dalam tubuh setiap manusia, dapat dipastikan bahwa kebugaran jasmani manusia tersebut baik dan dapat lebih nyaman dalam melakukan suatu kegiatan dengan optimal. Dengan demikian kebugaran jasmani harus dimiliki oleh setiap peserta didik, agar peserta didik mengikuti kegiatan pembelajaran dalam keaadan segar dan sehat serta tidak merasakan kelelahan yang berlebih. Sehingga dari pendidikan jasmani peserta didik dapat meningatkan dan menjaga tingkat kebugaran jasmaninya.

Pada dasarnya pemberian materi kebugaran jasmani di sekolah tergolong masih monoton, dimana guru masih menjadi sumber belajar satu-satunya. Apalagi dalam pelaksanaan pembelajaran materi kebugaran jasmani unsur kelincahan. Kelincahan adalah kemampuan seseorang mengubah arah gerak dengan cepat dan tanpa kehilangan keseimbangan (Horicka, Hianik, \& Šimonek, 2014; Ozmen \& Aydogmus, 2016). Kelincahan adalah suatu kemampuan tubuh dalam mengubah arah gerak dengan cepat yang dilakukan bersamaan dengan gerakan lainnya (Spiteri, Newton, \& Nimphius, 2015; Young \& Farrow, 2013). Kelincahan merupakan aktivitas gerak yang membutuhkan kecepatan dalam mengubah posisi tubuh dan bagian-bagiannya (Sudarsono, Saichudin, \& Andiana, 2020; Zahrina, 2021). Padahal dalam proses pembelajaran guru dapat menggunakan media yang dapat mempermudah penyampaian materi pembelajaran. Dengan tersedianya dan dimanfaatkannya media sumber belajar secara tepat dan konseptual maka akan memperkaya proses berlangsungnya pembelajaran, serta tersedianya sumber belajar yang memadai akan dapat mengatasi suatu hambatan yang ada dalam proses pembelajaran(Adi \& Fathoni, 2019; Fathoni, 2018). Menurut Adi \& Fathoni (2020b) media pembelajaran adalah alat atau metode yang digunakan dalam proses pembelajaran agar proses pembelajaran dapat berlangsung secara tepat guna. Menurut Media pembelajaran merupakan segala sesuatu yang digunakan untuk menarik perhatian dan merangsang minat siswa dalam proses pembelajaran (Al-Rahmi \& Zeki, 2017; Hakim, 2018). Media pembelajaran adalah alat komunikasi yang digunakan guru untuk menyampaikan informasi kepada peserta didik (Gikas \& Grant, 2013; Kumar Basak, Wotto, \& Bélanger, 2018). Dalam proses pembelajaran guru harus bisa mengkondisikan peserta didik agar fokus terhadap materi yang disampaikan dan tujuan pembelajaran dapat terlaksana dengan kondisi senang dan nyaman. Sehingga dengan kemajuan teknologi, seharusnya guru dapat memanfaatkan kemajuan teknologi dalam proses pembelajaran yaitu salah satunya dengan menggunakan multimedia interaktif agar tujuan pembelajaran dapat terlaksana dengan optimal.

Adanya perubahan dalam bidang teknologi informasi membawa pandangan baru terhadap materi pembelajaran (learning material) dan metode pembelajaran (learning method). Produk dari TI (Teknologi Informasi) telah memberikan alternatif berupa bahan ajar berbasis multimedia interaktif yang dapat diakses dan digunakan oleh peserta didik dalam bentuk software yang disimpan dalam DVD (Digital Versatile Disc), $\mathrm{CD}$ (Compact Disk), Flashdisk dan lain-lain. Multimedia interaktif adalah suatu media yang dirancang oleh desainer dengan tampilan yang memiliki interaktifitas dan bertujuan untuk memberikan pesan atau informasi kepada pengguna (Barbee \& Lowenstein, 2015; Leow \& Neo, 2014). Multimedia interaktif adalah gabungan dari teks, gambar, animasi, audio, dan video dengan tujuan untuk menyampaikan sebuah informasi secara menarik, serta perlu ditambahkannya unsur interaktivitas agar penyampaian informasi dapat tersampaikan dengan baik (Arono, 2014; Takacs, Swart, \& Bus, 2015). Terdapat beberapa karakteristik pembelajaran multimedia diantaranya yaitu (1) berisi konten materi dalam bentuk visual, audio, dan audiososial, (2) memiliki kekutan bahasa warna dan bahasa objek, (3) tipe pembelajaran yang bervariasi, (4) respon pembelajaran dan penguatan yang bervariasi, (5) dapat digunakan secara klasikal atau individual, (6) mengembangkan prinsip 
evaluasi diri dalam mengukur proses serta hasil belajar, dan (7) dapat digunakan offline dan online (Adi \& Fathoni, 2020a, 2020c). Program multimedia interaktif berbasis komputer memiliki nilai lebih dibandingkan bahan belajar tercetak seperti biasanya. Pembelajaran menggunakan multimedia interaktif mampu membuat peserta didik lebih aktif untuk belajar dengan motivasi yang tinggi karena ketertarikannya pada media pembelajaran yang mampu menampilkan teks, gambar, video, suara dan animasi.

SMP Negeri 4 Malang merupakan salah satu sekolah terbaik yang ada di Kota Malang. Dikatakan terbaik karena fasilitas untuk pembelajaran di sekolah tersebut sangat lengkap, terutama pada fasilitas di setiap kelas yang menyediakan $L C D$ (Liquid Crystal Display) dan proyektor yang merupakan alat penunjang untuk proses pembelajaran. Berdasarkan hasil observasi awal yang dilakukan oleh peneliti menggunakan analisis kebutuhan observasi dan penyebaran angket dengan menggunakan objek 100 siswa di SMP Negeri 4 Malang diperoleh hasil bahwa $98 \%$ siswa pernah memperoleh materi kebugaran jasmani unsur kelincahan dari buku ajar dan lembar kerja siswa. Sedangkan $48 \%$ siswa belum pernah mendapatkan materi kebugaran jasmani unsur kelincahan melalui multimedia interaktif. Hasil lain menunjukkan bahwa terdapat $52 \%$ siswa yang mendapatkan materi kebugaran jasmani unsur kelincahan dari video dan power point (PPT). Dengan hasil tersebut peneliti berasumsi bahwa siswa membutuhkan peningkatan penggunaan multimedia interaktif dalam pembelajaran kebugaran jasmani unsur kelincahan.

Hasil analisis kebutuhan yang telah diperoleh, peneliti beranggapan bahwa dibutuhkan pengembangan mengenai pembelajaran kebugaran jasmani unsur kelincahan berbasis multimedia interaktif di SMP Negeri 4 Malang. Dengan alasan agar dapat memaksimalkan penggunaan sarana pembelajaran yang telah disediakan di sekolah, utamanya penggunaan $L C D$ dan proyektor di setiap kelas, meningkatkan minat siswa mengikuti pembelajaran kebugaran jasmani unsur kelincahan karena sebelumnya pelaksanaan pembelajaran kebugaran jasmani unsur kelincahan masih monoton hanya bergantung pada buku ajar dan power point saja, dan meningkatkan keaktifan siswa saat melakukan kegiatan olahraga dilapangan dengan variasi latihan untuk meningkatkan kelincahan yang nantinya dicantumkan dalam produk pengembangan.

Penelitian sebelumnya menurut Kurniawan (2014) dalam penelitiannya yang berjudul "Pengembangan Pembelajaran Judo Teknik Bantingan Kyu dengan Media VCD untuk Pejudo PJSI (Persatuan Judo Seluruh Indonesia)" mengungkapkan bahwa media pembelajaran Judo teknik bantingan Kyu yang dikemas dalam bentuk $V C D$ meningkatkan keefektifan dan keefesiensian proses pembelajaran, serta dapat meningkatkan penguasaan teknik bantingan Kyu bagi atlet Judo dengan cepat dan benar. Menurut Wismayanti (2013) yang berjudul "Pengaruh Hasil Latihan Senam Kebugaran Jasmani 2012 dan Senam Aerobik Terhadap Peningkatan Kebugaran Jasmani Siswa Putri Kelas VII SMP Negeri 2 Purbalingga Tahun Ajaran 2013/2014" menyatakan bahwa latihan senam aerobik dan senam kebugaran jasmani memberikan pengaruh yang signifikan terhadap peningkatan kebugaran jasmani pada siswa putri kelas VII SMP N 2 Purbalingga Tahun ajaran 2013/2014. Hal tersebut dikarenakan senam kebugaran jasmani (SKJ) dan senam aerobik merupakan bentuk latihan yang bertujuan untuk meningkatkan kebugaran jasmani karena disetiap gerakannya melibatkan sejumlah otot-otot besar secara berkesinambungan. SKJ dan senam aerobik menggunakan bantuan iringan musik untuk melakukan gerakan-gerakan yang sistematik. Dengan iringan musik tersebut siswa perempuan akan tertarik dan bersemangat untuk mengikutiya. Sedangkan penelitian sebelumnya menurut Suwiwa, dkk (2014) dengan judul "Pengembangan Multimedia Interaktif Pembelajaran Pada Mata Kuliah Teori dan Praktik Pencak Silat" menyatakan bahwa hasil pembelajaran menggunakan multimedia interaktif meningkatkan hasil belajar mata kuliah teori dan praktek pencak silat. Hal tersebut dipengaruhi oleh multimedia interaktif yang menggunakan landasan teori komunikasi, sehingga pesan materi yang abstrak akan lebih jelas dan mudah dipahami dengan baik jika diberi bantuan gambar, video, audio, dan animasi. Dan penelitian sebelumnya menurut Fikri (2017) dengan judul "Meningkatkan Kebugaran Jamani Melalui Metode Latihan Sirkuit Dalam Pembelajaran Pendidikan Jasmani Olahraga dan Kesehatan Di SMA Negeri 1 Lubuklinggau" memaparkan hasil yaitu terdapat sebagian besar siswa kelas $X$ di SMA Negeri 1 Lubuklinggau memperoleh peningkatan pada kebugaran jasmaninya setelah mengikuti pembelajaran menggunakan metode latihan sirkuit selama dua siklus. Hal tersebut terlihat dari hasil tes yang menunjukkan peningkatan setelah melakukan pembelajaran menggunakan latihan sirkuit dari pada hasil tes awal sebelum diberi perlakuan.

Berdasarkan hasil penelitian sebelumnya terdapat beberapa keunggulan dari produk pengembangan peneliti yaitu proses pembelajaran materi kebugaran jasmani unsur kelincahan dapat dilaksanakan di dalam kelas dengan menggunakan media pembelajaran berbasis multimedia interaktif. Penggunaan multimedia interaktif tersebut didukung dengan menggunakan laptop/komputer, $L C D$, dan proyektor. Sehingga dapat memudahkan 
guru dalam menyampaikan materi pembelajaran dan mencapai tujuan pembelajaran. Tentunya materi kebugaran jasmani unsur kelincahan akan lebih mudah dipahami oleh peserta didik sebab dalam produk pengembangan ini materi yang disampaikan disertai dengan gambar dan video berbentuk variasi latihan kelincahan yang dikemas dalam bentuk permainan. Dan pemberian audio/musik untuk meningkatkan minat peserta didik dalam mengikuti pembelajaran. Serta pemberian soal-soal latihan mengenai kebugaran jasmani unsur kelincahan. Dengan adanya pengembangan ini juga diharapkan siswa dapat aktif dalam proses pembelajaran dan dapat meningkatkan motivasi belajar kebugaran jasmani unsur kelincahan, dan berjalannya pembelajaran dapat efektif serta efisien.

\section{METODE}

Model penelitian yang digunakan pada penelitian dan pengembangan ini yaitu menggunakan pendekatan Research and Development (R\&D) dengan menggunakan model pengembangan multimedia oleh Lee \& Owens (2004:93), dengan langkah-langkah penelitian sebagai berikut: (1) Analisis kebutuhan, (2) Melakukan desain produk, (3) Pengembangan produk, (4) Implementasi, dan (5) Evaluasi produk. Subjek uji coba pada penelitian pengembangan ini adalah ahli pembelajaran, ahli kebugaran jasmani, ahli media, guru PJOK kelas VII dan kelas VIII SMP Negeri 4 Malang, dan 80 peserta didik SMP Negeri 4 Malang yang terdiri dari 40 peserta didik kelas VII dan 40 Peserta didik kelas VIII. Dalam proses pengumpulan data, peneliti menggunakan instrumen angket atau kuesioner untuk mendapatkan data dari subjek penelitian. Dan data kuantitatif diperoleh dari hasil angket/kuesioner yang telah diisi oleh subjek penelitian. Teknik analisis data menggunakan analisis statistik deskriptif kuantitatif. Teknik pengukuran data menggunakan skala Likert. Jawaban dari setiap item instrument yang menggunakan skala Likert maka akan memiliki tingkatan dari sangat negatif hingga sangat positif. Proses menyimpulkan data hasil yang telah diperoleh digolongkan sesuai dengan persentase yang sudah didapat. Penggolongan persentase yang digunakan dapat dilihat pada tabel berikut:

Tabel 2. Kriteria Kualitas Produk (Jamshed, 2014; Leguina, 2015)

\begin{tabular}{ccl}
\hline Persentase & Keterangan & \multicolumn{1}{c}{ Makna } \\
\hline $75,01 \%-100 \%$ & Sangat Valid & Digunakan Tanpa Revisi \\
$50,01 \%-75,00 \%$ & Cukup Valid & Digunakan Dengan Revisi Kecil \\
$25,01 \%-50,00 \%$ & Tidak valid & Tidak Layak Digunakan \\
$00,00 \%-25,00 \%$ & Sangat Tidak Valid & Terlarang Digunakan \\
\hline
\end{tabular}

\section{HASIL}

Hasil analisis data digunakan untuk mengetahui kelayakan produk pengembangan pembelajaran kebugaran jasmani unsur kelincahan berbasis multimedia interaktif di SMP Negeri 4 Malang. Pada bagian ini menguraikan analisis data hasil pengumpulan data dari ahli pembelajaran, ahli media, ahli kebugaran jasmani, tinjauan pengguna yaitu guru pendidikan jasmani dan kesehatan kelas VII dan kelas VIII SMP Negeri 4 Malang serta data hasil uji coba kelompok kecil dan besar.

\section{Ahli Pembelajaran}

Analisis data yang dilakukan berdasarkan data hasil validasi ahli pembelajaran, masing-masing dari aspek tersebut akan dideskripsikan pada tabel berikut.

Tabel 3. Hasil Analisis Data Ahli Pembelajaran

\begin{tabular}{llrc}
\hline No. & Aspek & Kelayakan & Kategori \\
\hline 1 & KEJELASAN & $92 \%$ & SANGAT VALID \\
2 & KETEPATAN & $92 \%$ & SANGAT VALID \\
3 & KEMUDAHAN & $100 \%$ & SANGAT VALID \\
\hline RATA-RATA & $95 \%$ & SANGAT VALID \\
\hline
\end{tabular}




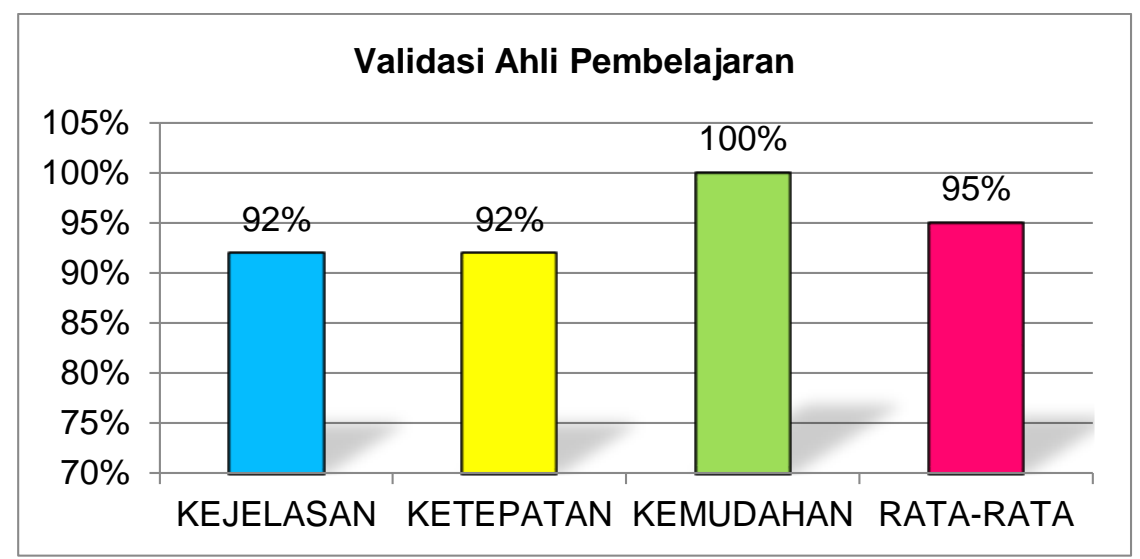

Gambar 1. Diagram Persentase Penilaian Ahli Pembelajaran Terhadap Produk Pengembangan Pembelajaran Kebugaran Jasmani Unsur Kelincahan Berbasis Multimedia Interaktif di SMP Negeri 4 Malang.

Berdasarkan hasil penilaian yang diperoleh dari ahli pembelajaran didapatkan rata-rata sebesar 95\%, kemudian hasil tersebut dikonversikan dengan tabel kualifikasi kelayakan menunjukkan bahwa produk pengembangan pembelajaran kebugaran jasmani unsur kelincahan berbasis multimedia interaktif di SMP Negeri 4 Malang telah memenuhi kriteria sangat valid sehingga layak digunakan untuk uji coba kelompok dengan revisi kecil.

\section{Ahli Media}

Analisis data yang dilakukan berdasarkan data hasil validasi ahli media, masing-masing dari aspek tersebut akan dideskripsikan pada tabel berikut.

Tabel 4. Hasil Analisis Data Ahli Media

\begin{tabular}{llrc}
\hline No. & Aspek & Kelayakan & Kategori \\
\hline $\mathbf{1}$ & KEJELASAN & $95 \%$ & SANGAT VALID \\
$\mathbf{2}$ & KELENGKAPAN & $75 \%$ & CUKUP VALID \\
$\mathbf{3}$ & KEMUDAHAN & $90 \%$ & SANGAT VALID \\
$\mathbf{4}$ & KEMENARIKAN & $88 \%$ & SANGAT VALID \\
$\mathbf{5}$ & KESESUAIAN & $91 \%$ & SANGAT VALID \\
$\mathbf{6}$ & KETEPATAN & $88 \%$ & SANGAT VALID \\
\hline RATA-RATA & $\mathbf{8 8 \%}$ & SANGAT VALID \\
\hline
\end{tabular}

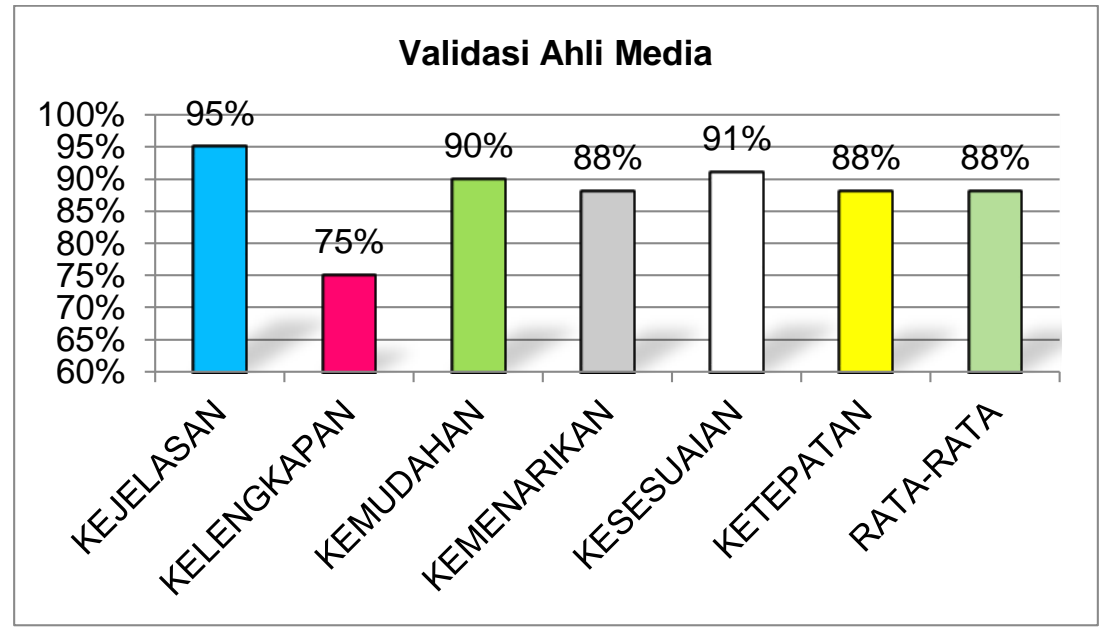

Gambar 1. Diagram Persentase Penilaian Ahli Media Terhadap Produk Pengembangan Pembelajaran Kebugaran Jasmani Unsur Kelincahan Berbasis Multimedia Interaktif di SMP Negeri 4 Malang.

Berdasarkan hasil penilaian yang diperoleh dari ahli media didapatkan rata-rata sebesar $88 \%$, kemudian hasil tersebut dikonversikan dengan tabel kualifikasi kelayakan menunjukkan bahwa produk pengembangan 
pembelajaran kebugaran jasmani unsur kelincahan berbasis multimedia interaktif di SMP Negeri 4 Malang telah memenuhi kriteria sangat valid sehingga layak digunakan untuk uji coba kelompok.

\section{Ahli Kebugaran Jasmani}

Analisis data yang dilakukan berdasarkan data hasil validasi ahli kebugaran jasmani, masing-masing dari aspek tersebut akan dideskripsikan pada tabel berikut.

Tabel 5. Hasil Analisis Data Ahli Kebugaran Jasmani

\begin{tabular}{llcc}
\hline No. & Aspek & Kelayakan & Kategori \\
\hline $\mathbf{1}$ & KEJELASAN & $88 \%$ & SANGAT VALID \\
$\mathbf{2}$ & KETEPATAN & $100 \%$ & SANGAT VALID \\
$\mathbf{3}$ & KEMUDAHAN & $75 \%$ & CUKUP VALID \\
$\mathbf{4}$ & KEMENARIKAN & $75 \%$ & CUKUP VALID \\
$\mathbf{5}$ & KESESUAIAN & $100 \%$ & SANGAT VALID \\
\hline RATA-RATA & & $\mathbf{8 8 \%}$ & SANGAT VALID \\
\hline
\end{tabular}

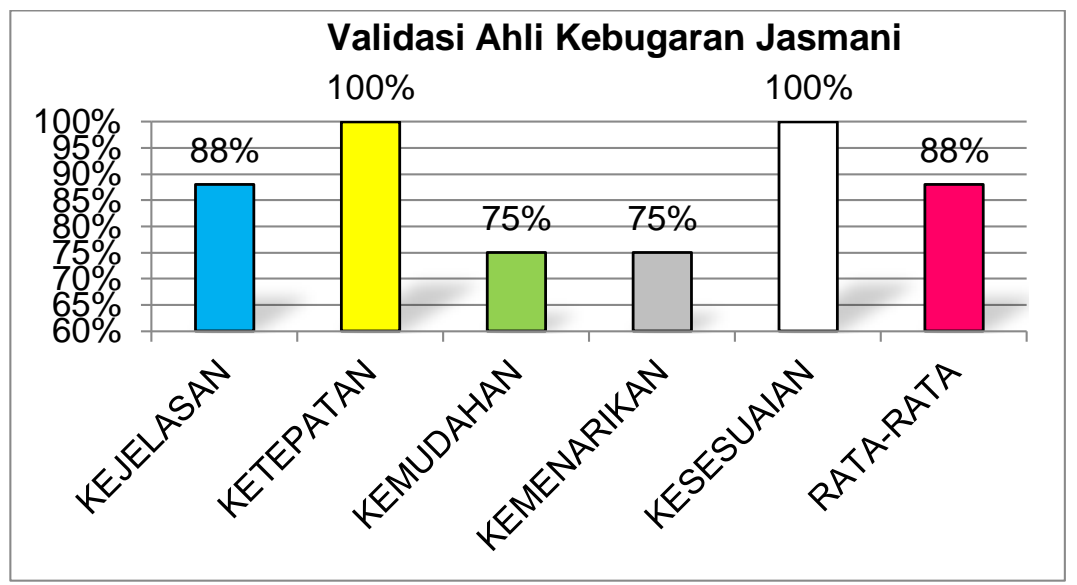

Gambar 2. Diagram Persentase Penilaian Ahli Kebugaran Jasmani Terhadap Produk Pengembangan Pembelajaran Kebugaran Jasmani Unsur Kelincahan Berbasis Multimedia Interaktif di SMP Negeri 4 Malang.

Berdasarkan hasil penilaian yang diperoleh dari ahli kebugaran jasmani didapatkan rata-rata sebesar $88 \%$, kemudian hasil tersebut dikonversikan dengan tabel kualifikasi kelayakan menunjukkan bahwa produk pengembangan pembelajaran kebugaran jasmani unsur kelincahan berbasis multimedia interaktif di SMP Negeri 4 Malang telah memenuhi kriteria sangat valid sehingga layak digunakan untuk uji coba kelompok dengan revisi kecil.

\section{Tinjauan Pengguna}

Analisis data yang dilakukan berdasarkan data hasil tinjauan pengguna yang merupakan guru pendidikan jasmani, olahraga, dan kesehatan kelas VII dan kelas VIII SMP Negeri 4 Malang, masing-masing aspek dari tinjauan pengguna akan dideskripsikan pada tabel berikut.

Hasil Tinjauan Pengguna Guru Pendidikan Jasmani, Olahraga, dan Kesehatan Kelas VII

Tabel 6. Hasil Analisis Data Tinjauan Guru PJOK Kelas VII

\begin{tabular}{llll}
\hline No. & Aspek & Kelayakan & Kategori \\
\hline 1 & KEJELASAN & $79 \%$ & SANGAT VALID \\
2 & KEMENARIKAN & $81 \%$ & SANGAT VALID \\
3 & KEMUDAHAN & $80 \%$ & SANGAT VALID \\
4 & KEGUNAAN & $88 \%$ & SANGAT VALID \\
5 & KESESUAIAN & $79 \%$ & SANGAT VALID \\
\hline RATA-RATA & $81 \%$ & SANGAT VALID \\
\hline
\end{tabular}




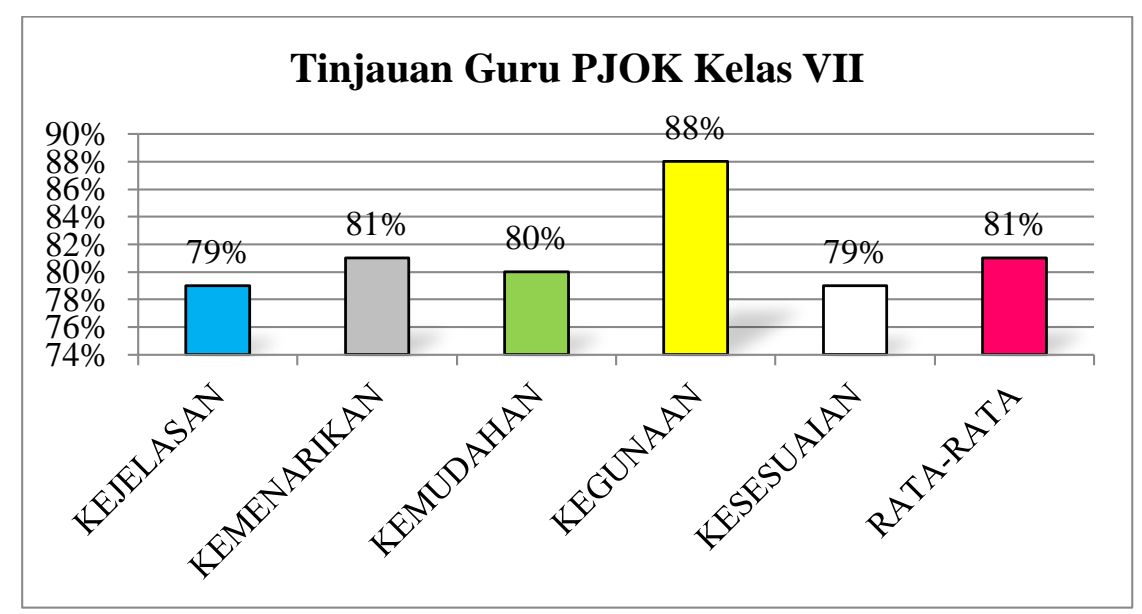

Gambar 3. Diagram Persentase Penilaian Tinjauan Guru PJOK Kelas VII Terhadap Produk Pengembangan Pembelajaran Kebugaran Jasmani Unsur Kelincahan Berbasis Multimedia Interaktif di SMP Negeri 4 Malang.

Berdasarkan hasil penilaian yang diperoleh dari tinjauan pengguna yang merupakan guru PENJASKES kelas VII SMP Negeri 4 Malang didapatkan rata-rata sebesar $81 \%$, kemudian hasil tersebut dikonversikan dengan tabel kualifikasi kelayakan menunjukkan bahwa produk pengembangan pembelajaran kebugaran jasmani unsur kelincahan berbasis multimedia interaktif di SMP Negeri 4 Malang telah memenuhi kriteria cukup valid sehingga layak digunakan untuk uji coba kelompok dengan revisi.

Hasil Tinjauan Pengguna Guru Pendidikan Jasmani, Olahraga, dan Kesehatan Kelas VIII

Tabel 7. Hasil Analisis Data Tinjauan Guru PJOK Kelas VIII

\begin{tabular}{llcc}
\hline No. & Aspek & Kelayakan & Kategori \\
\hline 1 & KEJELASAN & $100 \%$ & SANGAT VALID \\
2 & KEMENARIKAN & $86 \%$ & SANGAT VALID \\
3 & KEMUDAHAN & $100 \%$ & SANGAT VALID \\
4 & KEGUNAAN & $100 \%$ & SANGAT VALID \\
5 & KESESUAIAN & $93 \%$ & SANGAT VALID \\
\hline RATA-RATA & $96 \%$ & SANGAT VALID \\
\hline
\end{tabular}

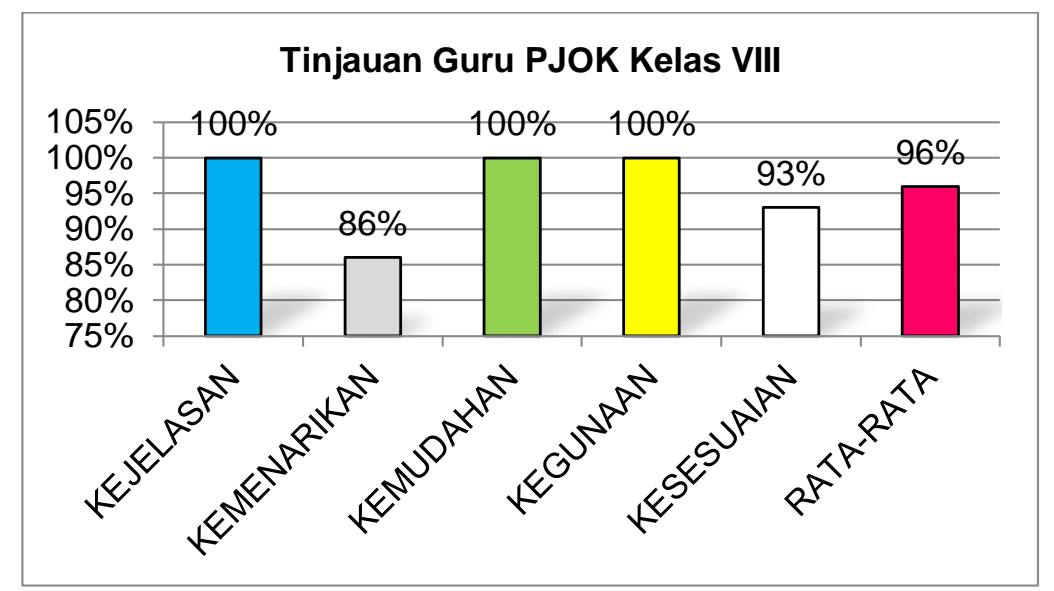

Gambar 4. Diagram Persentase Penilaian Tinjauan Guru PJOK Kelas VIII Terhadap Produk Pengembangan Pembelajaran Kebugaran Jasmani Unsur Kelincahan Berbasis Multimedia Interaktif di SMP Negeri 4 Malang.

Berdasarkan hasil penilaian yang diperoleh dari tinjauan pengguna yang merupakan guru PENJASKES kelas VIII SMP Negeri 4 Malang didapatkan rata-rata sebesar 96\%, kemudian hasil tersebut dikonversikan dengan tabel kualifikasi kelayakan menunjukkan bahwa produk pengembangan pembelajaran kebugaran jasmani 
unsur kelincahan berbasis multimedia interaktif di SMP Negeri 4 Malang telah memenuhi kriteria sangat valid sehingga layak digunakan untuk uji coba kelompok.

\section{Uji Coba Kelompok Kecil}

Analisis data dilakukan berdasarkan data hasil uji coba kelompok kecil kelas VII dan Kelas VIII, masing-masing dari aspek tersebut akan dideskripsikan pada tabel-tabel berikut ini.

Tabel 8. Hasil Analisis Data Uji Coba Kelompok Kecil Kelas VII dengan $n=10$

\begin{tabular}{llll}
\hline No. & Aspek & Kelayakan & Kategori \\
\hline 1 & KEJELASAN & $88 \%$ & SANGAT VALID \\
2 & KEMENARIKAN & $89 \%$ & SANGAT VALID \\
3 & KEMUDAHAN & $86 \%$ & SANGAT VALID \\
4 & KEGUNAAN & $94 \%$ & SANGAT VALID \\
5 & KESESUAIAN & $89 \%$ & SANGAT VALID \\
\hline RATA-RATA & $89 \%$ & SANGAT VALID \\
\hline
\end{tabular}

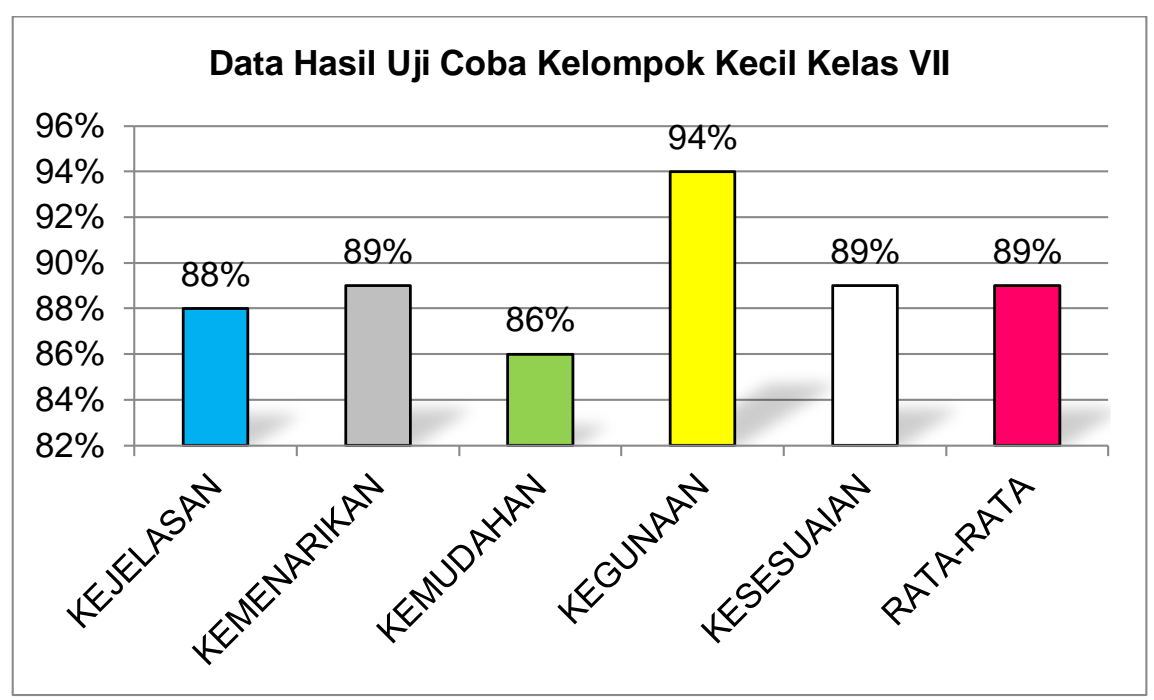

Gambar 4.5. Diagram Persentase Uji Coba Kelompok Kecil Kelas VII SMP Negeri 4 Malang.

Berdasarkan tabel analisis data di atas dengan persentase tingkat kelayakan diperoleh skor rata-rata keseluruhan $89 \%$, kemudian dikonversikan dengan tabel kualifikasi kelayakan maka produk pengembangan pembelajaran kebugaran jasmani unsur kelincahan berbasis multimedia interaktif di SMP Negeri 4 Malang dapat digunakan.

Tabel 9. Hasil Analisis Data Uji Coba Kelompok Kecil Kelas VIII dengan $n=10$

\begin{tabular}{llcl}
\hline No. & Aspek & Kelayakan & Kategori \\
\hline 1 & KEJELASAN & $87 \%$ & SANGAT VALID \\
2 & KEMENARIKAN & $88 \%$ & SANGAT VALID \\
3 & KEMUDAHAN & $87 \%$ & SANGAT VALID \\
4 & KEGUNAAN & $93 \%$ & SANGAT VALID \\
5 & KESESUAIAN & $88 \%$ & SANGAT VALID \\
\hline RATA-RATA & & $88 \%$ & SANGAT VALID \\
\hline
\end{tabular}




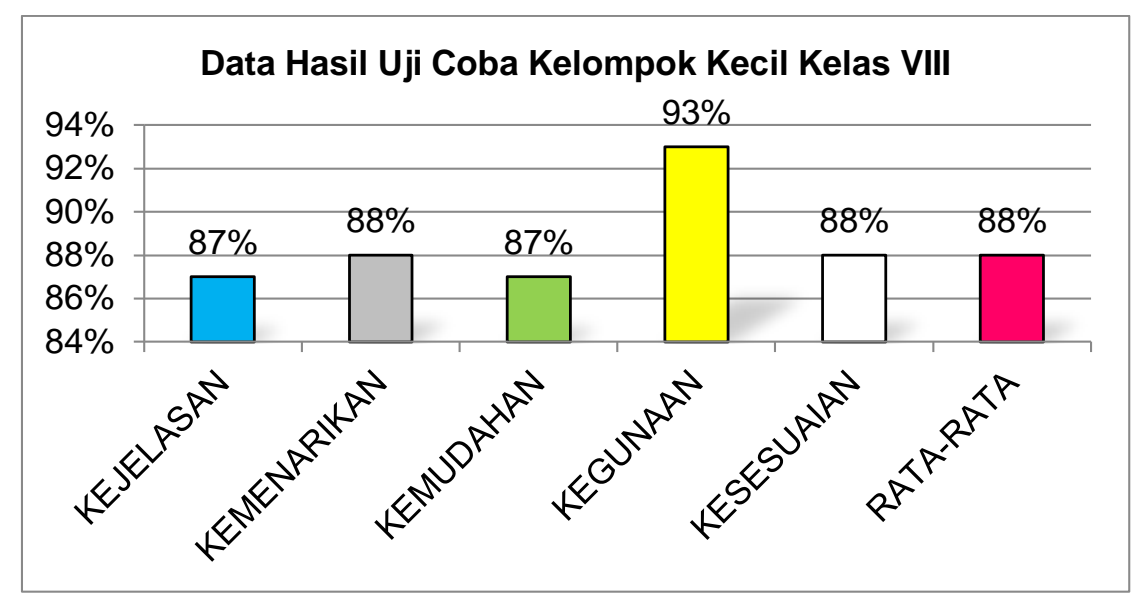

Gambar 6. Diagram Persentase Uji Coba Kelompok Kecil Kelas VIII SMP Negeri 4 Malang.

Berdasarkan tabel analisis data di atas dengan persentase tingkat kelayakan diperoleh skor rata-rata keseluruhan $88 \%$, kemudian dikonversikan dengan tabel kualifikasi kelayakan maka produk pengembangan pembelajaran kebugaran jasmani unsur kelincahan berbasis multimedia interaktif di SMP Negeri 4 Malang dapat digunakan.

\section{Uji Coba Kelompok Besar}

Analisis data dilakukan berdasarkan data hasil uji coba kelompok besar kelas VII dan Kelas VIII, masingmasing dari aspek tersebut akan dideskripsikan pada tabel-tabel berikut ini.

Tabel 10. Hasil Analisis Data Uji Coba Kelompok Besar Kelas VII dengan $n=30$

\begin{tabular}{llll}
\hline No. & Aspek & Kelayakan & Kategori \\
\hline 1 & KEJELASAN & $89 \%$ & SANGAT VALID \\
2 & KEMENARIKAN & $88 \%$ & SANGAT VALID \\
3 & KEMUDAHAN & $88 \%$ & SANGAT VALID \\
4 & KEGUNAAN & $90 \%$ & SANGAT VALID \\
5 & KESESUAIAN & $87 \%$ & SANGAT VALID \\
\hline RATA-RATA & $88 \%$ & SANGAT VALID \\
\hline
\end{tabular}

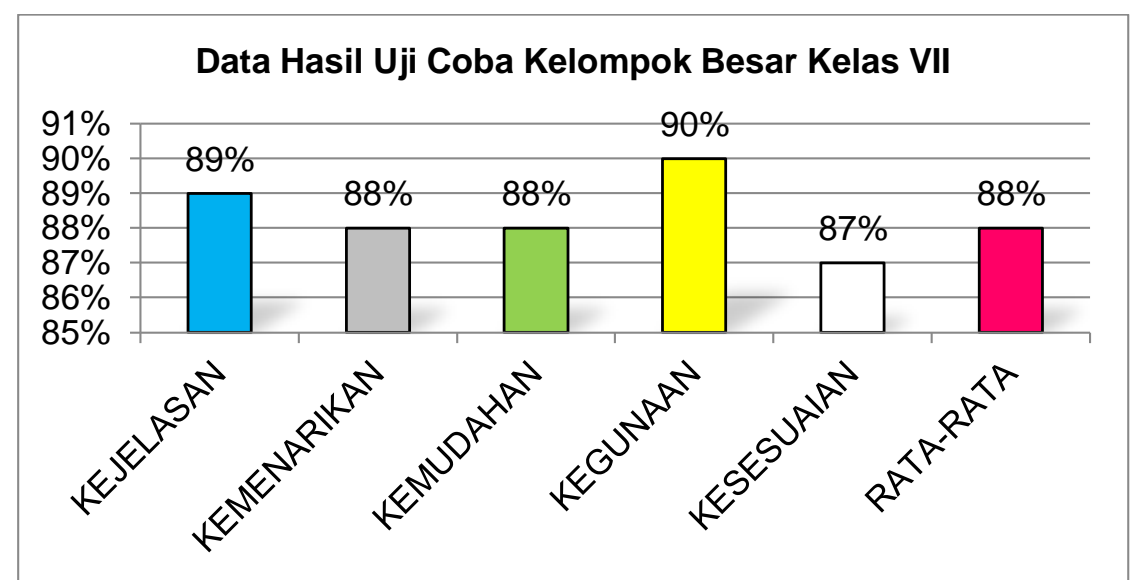

Gambar 7. Diagram Persentase Uji Coba Kelompok Besar Kelas VII SMP Negeri 4 Malang.

Berdasarkan tabel analisis data di atas dengan persentase tingkat kelayakan diperoleh skor rata-rata keseluruhan $88 \%$, kemudian dikonversikan dengan tabel kualifikasi kelayakan maka produk pengembangan pembelajaran kebugaran jasmani unsur kelincahan berbasis multimedia interaktif di SMP Negeri 4 Malang dapat digunakan 
Tabel 11. Hasil Analisis Data Uji Coba Kelompok Besar Kelas VIII dengan $n=30$

\begin{tabular}{llcc}
\hline No. & Aspek & Kelayakan & Kategori \\
\hline 1 & KEJELASAN & $89 \%$ & SANGAT VALID \\
2 & KEMENARIKAN & $90 \%$ & SANGAT VALID \\
3 & KEMUDAHAN & $89 \%$ & SANGAT VALID \\
4 & KEGUNAAN & $92 \%$ & SANGAT VALID \\
5 & KESESUAIAN & $88 \%$ & SANGAT VALID \\
\hline RATA-RATA & $90 \%$ & SANGAT VALID \\
\hline
\end{tabular}

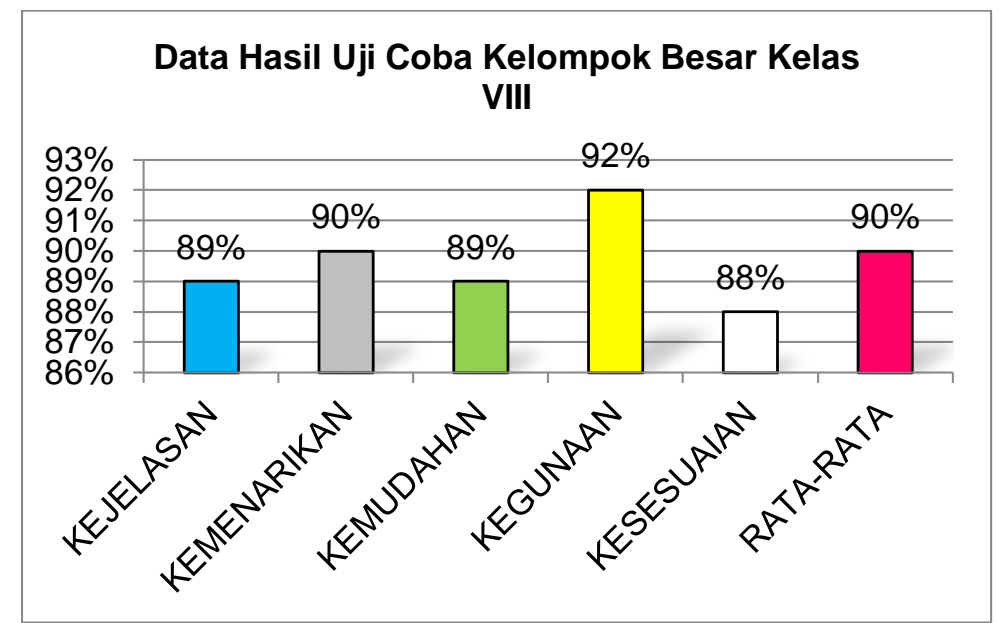

Gambar 8. Diagram Persentase Uji Coba Kelompok Besar Kelas VIII SMP Negeri 4 Malang.

Berdasarkan tabel analisis data di atas dengan persentase tingkat kelayakan diperoleh skor rata-rata keseluruhan $90 \%$, kemudian dikonversikan dengan tabel kualifikasi kelayakan maka produk pengembangan pembelajaran kebugaran jasmani unsur kelincahan berbasis multimedia interaktif di SMP Negeri 4 Malang dapat digunakan.

\section{PEMBAHASAN}

Produk pengembangan pembelajaran kebugaran jasmani unsur kelincahan berbasis multimedia interaktif ini dikemas dalam aplikasi autoplay media studio. Produk pengembangan ini memaparkan materi kebugaran jasmani unsur kelincahan menggunakan teks, gambar, audio, serta video. Sesuai pendapat bahwa multimedia interaktif adalah gabungan dari teks, gambar, animasi, suara, dan video untuk menyampaikan sebuah produk secara menarik (Florence Martin, Jerome Hoskins, Robin Brooks, 2013; Meixner, 2017). Dengan demikian produk pengembangan ini memiliki unsur interaktivitas sehingga penyampaian materi dapat tersampaikan dengan baik dan efektif serta dapat mencapai tujuan pembelajaran dengan maksimal. Produk ini dikhususkan digunakan dalam pembelajaran kebugaran jasmani unsur kelincahan di SMP Negeri 4 Malang untuk kelas VII dan kelas VIII. Karena dalam produk ini terdapat latihan untuk meningkatkan kelincahan sesuai dengan $\mathrm{KI}$ dan KD PJOK kelas VII dan VII yang menyatakan bahwa mempraktikkan latihan peningkatan derajat kebugaran jasmani yang terkait dengan kesehatan dan pengukuran hasilnya. Latihan kelincahan dalam produk ini disajikan dalam bentuk permainan, karena dengan permainan atau modifikasi suatu latihan dalam pembelajaran PJOK dapat meningkatkan minat dan ketertarikan siswa untuk mengikuti proses pembelajaran (Althoff, White, \& Horvitz, 2016; Lyons et al., 2016). Isi dari multimedia interaktif ini yaitu terdapat pengertian kebugaran jasmani, pengertian kelincahan menurut, variasi permainan untuk meningkatkan kelincahan yang terdiri dari 4 variasi permainan untuk kelas VII dan 4 variasi permainan untuk kelas VIII, sarana dan prasarana untuk pelaksanaan permainan, serta evaluasi berupa latihan soal. 


\section{KESIMPULAN}

Hasil penelitian dan pengembangan pembelajaran kebugaran jasmani unsur kelincahan berbasis multimedia interaktif yang dilakukan, maka dapat diambil kesimpulan bahwa produk pengembangan pembelajaran kebugaran jasmani unsur kelincahan berbasis multimedia interaktif di SMP Negeri 4 Malang layak digunakan sebagai media pendukung dalam pembelajaran, agar pembelajaran dapat berjalan dengan baik serta tujuantujuan pembelajaran dapat tercapai dengan maksimal.

\section{DAFTAR PUSTAKA}

Adi, S., \& Fathoni, A. F. (2019). Development of Learning Model Based on Blended Learning in Sports School. https://doi.org/10.2991/acpes-19.2019.2

Adi, S., \& Fathoni, A. F. (2020a). Blended Learning Analysis for Sports Schools in Indonesia. International Journal of Interactive Mobile Technologies (IJIM), 14(12), 149-164. Retrieved from https://www.onlinejournals.org/index.php/i-jim/index

Adi, S., \& Fathoni, A. F. (2020b). Mobile Learning sebagai Fasilitas Belajar Mandiri Pembelajaran Senam Lantai pada Mahasiswa Jurusan IImu Keolahragaan. Jurnal Pendidikan: Teori, Penelitian, Dan Pengembangan, 5(8), 1158-1166. Retrieved from http://journal.um.ac.id/index.php/jptpp/article/view/13946/6206

Adi, S., \& Fathoni, A. F. (2020c). The effectiveness and efficiency of blended learning at sport schools in Indonesia. International Journal of Innovation, Creativity and Change.

Al-Rahmi, W. M., \& Zeki, A. M. (2017). A model of using social media for collaborative learning to enhance learners' performance on learning. Journal of King Saud University - Computer and Information Sciences. https://doi.org/10.1016/j.jksuci.2016.09.002

Althoff, T., White, R. W., \& Horvitz, E. (2016). Influence of pokémon go on physical activity: Study and implications. Journal of Medical Internet Research. https://doi.org/10.2196/jmir.6759

Arono. (2014). Improving students listening skill through interactive multimedia in Indonesia. Journal of Language Teaching and Research. https://doi.org/10.4304/jttr.5.1.63-69

Barbee, D. E., \& Lowenstein, R. B. (2015). Interactive Multimedia. Information Resources Management Journal. https://doi.org/10.4018/irmj.1993100101

Darmawan, I. (2017). Upaya Meningkatkan Kebugaran Jasmani Siswa melalui Penjas. Jip.

Fathoni, A. F. (2018). The Role of Blended Learning on Cognitive Step in Education of Sport Teaching by Adjusting the Learning Style of the Students. https://doi.org/10.2991/isphe-18.2018.49

Fikri, A. (2017). Meningkatkan Kebugaran Jasmani Melalui Metode Latihan Sirkuit Dalam Pembelajaran Pendidikan Jasmani Olahraga dan Kesehatan Di SMA Negeri 1 Lubuklinggau. Jurnal Pembelajaran Olahraga, 1(2), 11-20.

Fikri, Azizil. (2017). Meningkatkan Kebugaran Jasmani Melalui Metode Latihan Sirkuit Dalam Pembelajaran Pendidikan Jasmani Olahraga Dan Kesehatan Di SMA Negeri 1 Lubuklinggau. Jurnal Pembelajaran Olahraga.

Florence Martin, Jerome Hoskins, Robin Brooks, T. B. (2013). Development of an Interactive Multimedia Instructional Module. Journal of Applied Instructional Design.

Gikas, J., \& Grant, M. M. (2013). Mobile computing devices in higher education: Student perspectives on learning with cellphones, smartphones \& social media. Internet and Higher Education. https://doi.org/10.1016/j.iheduc.2013.06.002

Hakim, L. (2018). PENGEMBANGAN MEDIA PEMBELAJARAN PAI BERBASIS AUGMENTED REALITY. Lentera Pendidikan : Jurnal IImu Tarbiyah Dan Keguruan. https://doi.org/10.24252/lp.2018v21n1i6

Harris, J., Cale, L., \& Musson, H. (2012). Physical Education and Sport Pedagogy. Physical Education and Sport Pedagogy. 
Harvey, S., Kirk, D., \& O'Donovan, T. M. (2014). Sport Education as a pedagogical application for ethical development in physical education and youth sport. Sport, Education and Society. https://doi.org/10.1080/13573322.2011.624594

Harvey, S., \& O'Donovan, T. M. (2013). Pre-service physical education teachers' beliefs about competition in physical education. Sport, Education and Society. https://doi.org/10.1080/13573322.2011.610784

Horicka, P., Hianik, J., \& Šimonek, J. (2014). The relationship between speed factors and agility in sport games. Journal of Human Sport and Exercise. https://doi.org/10.4100/jhse.2014.91.06

Huotari, P. R. T., Mikkelsson, L., Kujala, U. M., Laakso, L., \& Nupponen, H. (2013). Physical activity and fitness in adolescence as predictors of self-estimated fitness in adulthood. Journal of Sports Medicine and Physical Fitness.

Jamshed, S. (2014). Qualitative research method-interviewing and observation. Journal of Basic and Clinical Pharmacy. https://doi.org/10.4103/0976-0105.141942

Johnson, M. (2016). Adapted Physical Education and Sport. Adapted Physical Activity Quarterly. https://doi.org/10.1123/apaq.28.4.368

Kumar Basak, S., Wotto, M., \& Bélanger, P. (2018). E-learning, M-learning and D-learning: Conceptual definition and comparative analysis. E-Learning and Digital Media. https://doi.org/10.1177/2042753018785180

Kurniawan, A. W. (2014). Pengembangan Pembelajaran Judo Teknik Bantingan Kyu 4 dengan Media VCD untuk Pejudo PJSI (Persatuan Judo Seluruh Indonesia). Gelanggang Pendidikan Jasmani Indonesia, 2(1), 10-17.

Kwon, E. H., \& Block, M. E. (2017). Implementing the adapted physical education E-learning program into physical education teacher education program. Research in Developmental Disabilities. https://doi.org/10.1016/j.ridd.2017.07.001

Leguina, A. (2015). A primer on partial least squares structural equation modeling (PLS-SEM). International Journal of Research \& Method in Education. https://doi.org/10.1080/1743727x.2015.1005806

Leow, F. T., \& Neo, M. (2014). Interactive multimedia learning: Innovating classroom education in a Malaysian university. Turkish Online Journal of Educational Technology.

Lloyd, R. S., \& Oliver, J. L. (2012). The youth physical development model: A new approach to long-term athletic development. Strength and Conditioning Journal. https://doi.org/10.1519/SSC.0b013e31825760ea

López-Pastor, V. M., Kirk, D., Lorente-Catalán, E., MacPhail, A., \& Macdonald, D. (2013). Alternative assessment in physical education: A review of international literature. Sport, Education and Society. https://doi.org/10.1080/13573322.2012.713860

Lyons, E. J., Baranowski, T., Basen-Engquist, K. M., Lewis, Z. H., Swartz, M. C., Jennings, K., \& Volpi, E. (2016). Testing the effects of narrative and play on physical activity among breast cancer survivors using mobile apps: Study protocol for a randomized controlled trial. BMC Cancer. https://doi.org/10.1186/s12885-016-2244-y

Meixner, B. (2017). Hypervideos and interactive multimedia presentations. ACM Computing Surveys. https://doi.org/10.1145/3038925

Milanović, Z., Pantelić, S., Trajković, N., Sporiš, G., Kostić, R., \& James, N. (2013). Age-related decrease in physical activity and functional fitness among elderly men and women. Clinical Interventions in Aging. https://doi.org/10.2147/CIA.S44112

Mora-Gonzalez, J., Esteban-Cornejo, I., Cadenas-Sanchez, C., Migueles, J. H., Molina-Garcia, P., RodriguezAyllon, M., ... Ortega, F. B. (2019). Physical Fitness, Physical Activity, and the Executive Function in Children with Overweight and Obesity. Journal of Pediatrics. https://doi.org/10.1016/j.jpeds.2018.12.028

Ozmen, T., \& Aydogmus, M. (2016). Effect of core strength training on dynamic balance and agility in adolescent badminton players. Journal of Bodywork and Movement Therapies. 
https://doi.org/10.1016/j.jbmt.2015.12.006

Prakoso, D. P., \& Setiyo Hartoto. (2015). Pengukuran Tingkat Kebugaran Jasmani Terhadap Siswa Yang Mengikuti Ekstrakulikuler Bolavoli di SMS DR.Soetomo Surabaya. Jurnal Pendidikan Olahraga Dan Kesehatan.

Rink, J. E. (2013). Measuring teacher effectiveness in physical education. Research Quarterly for Exercise and Sport. https://doi.org/10.1080/02701367.2013.844018

Smith, N. J., Monnat, S. M., \& Lounsbery, M. A. F. (2015). Physical Activity in Physical Education: Are Longer Lessons Better? Journal of School Health. https://doi.org/10.1111/josh.12233

Solmon, M. A. (2015). Optimizing the role of physical education in promoting physical activity: A socialecological approach. Research Quarterly for Exercise and Sport. https://doi.org/10.1080/02701367.2015.1091712

Spiteri, T., Newton, R. U., \& Nimphius, S. (2015). Neuromuscular strategies contributing to faster multidirectional agility performance. Journal of Electromyography and Kinesiology. https://doi.org/10.1016/j.jelekin.2015.04.009

Sudarsono, H., Saichudin, \& Andiana, O. (2020). Hubungan Dynamic Stretching Dengan Kelincahan Penghobi Futsal Member Di Champions Singosari. Sport Science and Health, 2(1), 58-66. Retrieved from http://journal2.um.ac.id/index.php/jik/issue/archive

Suwiwa, Santyasa, \& K. (2014). Pengembangan Multimedia Interaktif Pembelajaran Pada Mata Kuliah Teori dan Praktik Pencak Silat. E-Journal Program Pascasarjana Universitas Pendidikan Ganesha Program Studi Teknologi Pembelajaran, 4(1), 1-12.

Takacs, Z. K., Swart, E. K., \& Bus, A. G. (2015). Benefits and Pitfalls of Multimedia and Interactive Features in Technology-Enhanced Storybooks: A Meta-Analysis. Review of Educational Research. https://doi.org/10.3102/0034654314566989

Wallhead, T. L., Garn, A. C., \& Vidoni, C. (2014). Effect of a sport education program on motivation for physical education and leisure-time physical activity. Research Quarterly for Exercise and Sport. https://doi.org/10.1080/02701367.2014.961051

Wismayanti, M. (2013). Pengaruh Hasil Latihan Senam Kebugaran Jasmani 2012 dan Senam Aerobik Terhaadap Peningkatan Kebugaran Jasmani Siswa Putri Kelas VII SMP N 2 Purbalingga Tahun 2013/2014. Universitas Negeri Semarang.

Young, W., \& Farrow, D. (2013). The importance of a sport-specific stimulus for training agility. Strength and Conditioning Journal. https://doi.org/10.1519/SSC.0b013e31828b6654

Zahrina, K. (2021). Pengaruh Latihan Kelincahan Dribble Bentuk T-Drill Langsung dan Tidak Langsung terhadap Peningkatan Kemampuan Keterampilan Dribble Peserta Kegiatan Ekstrakurikuler Bolabasket. Sport Science and Health, 3(1), 26-33. Retrieved from http://journal2.um.ac.id/index.php/jik/issue/archive 